Madrygal. Revista de Estudios Gallegos

ISSN: 1138-9664

\title{
O retorno e os conflitos da identidade
}

\author{
María Jesús Piñeiro Domínguez ${ }^{1}$
}

Recibido: 30 de maio de 2019 / Aceptado: 10 de setembro de 2019

Resumo. A emigración da poboación galega na posguerra foi moi elevada, como elevado foi tamén o retorno das persoas emigradas, especialmente durante a transición. Para elas, non só foi difícil a marcha do país, senón tamén o regreso a un lugar en aparente democracia, mais aínda en conflito polas feridas non reparadas da contenda. A través da lectura de ensaios e novelas centrados no retorno, preténdese convidar á reflexión sobre as consecuencias do regreso ao lugar de orixe e analizar a súa repercusión nos ámbitos familiar, social e político, entre outros. Falamos de ruptura da identidade, de inadaptación crónica, de choque xeracional, de decepción, desengano ou desarraigo, situacións todas elas que evidencian os conflitos dunha identidade en permanente (de)construción.

Palabras chave: migración; posguerra; retorno; identidade; narrativa.

\section{[es] El retorno y los conflictos de la identidad}

Resumen. La emigración de la población gallega durante la posguerra fue muy elevada, como elevado fue también el retorno de las personas emigradas, especialmente durante la transición. Para ellas, no solo fue difícil la salida del país, sino también el regreso a un lugar en aparente democracia, pero aún en conflicto por las heridas no reparadas de la contienda. A través de la lectura de ensayos y novelas centrados en el retorno, se pretende invitar a una reflexión sobre las consecuencias del regreso al lugar de origen y analizar su repercusión en los ámbitos familiar, social y político, entre otros. Hablamos de ruptura de identidad, de inadaptación crónica, de choque generacional, de decepción, de desengaño o desarraigo, situaciones todas ellas que evidencian los conflictos de una identidad en permanente (de)construcción.

Palabras clave: migración; posguerra; retorno; identidad; narrativa.

\section{[en] Return Migration and Identity Conflicts}

Abstract. The emigration of the Galician population during the postwar period was very high, as well as the number of migrants that came back, especially during the transition. For them, it was difficult leaving the country and also returning to a place in apparent democracy, but still in conflict because of the unrestored wounds of the war. The analysis of several essays and novels focused on the return will allow us to reflect on the consequences of coming back to the origins and its impact on family, social and political areas, among others. We talk about identity break-up, chronic maladjustment, generational clash, disappointment, or uprooting, as an example of situations that evidence how identity is in conflict and in permanent (de)construction.

Keywords: Migration, Postwar Period; Return; Identity; Narrative.

Sumario. 1. Introdución. 2. O retorno na vida real. 2.1. Unha visión psicolóxica. 2.2. Unha visión antropolóxica. 3. O retorno na ficción: narrativas do regreso. 4. Conclusións. 5. Referencias bibliográficas.

Como citar: Piñeiro Domínguez, Ma J. (2020): “O retorno e os conflitos da identidade”, en Madrygal. Revista de Estudios Gallegos 23 Núm. Especial, pp. 285-291.

1 Universidad Complutense de Madrid. Facultade de Filoloxía. Programa de doutoramento Estudos Literarios.

Correo-e: mariajpi@ucm.es; http://orcid.org/0000-0002-2334-4741. 


\section{Introdución}

Con frecuencia, cando se fala do exilio ou da emigración, centrámonos nos que marcharon; nos que abandonaron a terra natal. Analizamos as circunstancias da súa marcha, as dificultades que atoparon, as sensacións que tiveron ao chegar a un novo lugar, a morriña que sentiron, a adaptación a unha nova cultura... Mais poucas veces nos poñemos no lugar de quen emprende o camiño de volta e regresa ás súas orixes enfrontándose a unha nova emigración.

En realidade, o retorno á terra natal acontece con bastante frecuencia na vida real, e sabemos que ten consecuencias visibles nas vidas das persoas emigradas e no seu contorno. Pero por diversos motivos, este fenómeno apenas está visibilizado e incluso queda nun discreto segundo plano pola incomodidade que parece provocar. Talvez pensamos, probablemente con certa lóxica, que retornar á terra de orixe é un premio ou unha recompensa; unha experiencia satisfactoria, gratificante ou feliz en calquera caso. Pero a realidade é ben distinta, e non temos en conta que o retorno é duro e que supón o abandono, por segunda vez, da seguridade que proporciona o coñecido.

Coa intención de reflexionar sobre o que implica o regreso e como repercute nos ámbitos familiar, social e político, entre outros, proponse unha análise baseada na lectura dunha selección de textos centrados no retorno que nos permitirán comprender este fenómeno desde dúas perspectivas. Por un lado, abordaremos o retorno na vida real a través de dúas disciplinas: a psiquiatría, que compila testemuñas reais de retornados que, por mor do regreso, precisaron atención sanitaria; e a antropoloxía, que ofrece unha visión do regreso a partir de entrevistas reais a emigrantes e retornados de todo o mundo. Por outro lado, falaremos do retorno na ficción, exemplificado pola literatura a través das tramas e dos personaxes, pero tamén, mediante as experiencias dos propios escritores.

\section{O retorno na vida real}

A emigración, e mais a súa incidencia a nivel individual e colectivo, está plenamente documentada en multitude de ensaios e estudos psicolóxicos, sociolóxicos e antropolóxicos, entre outros. É lóxico que sexa así, xa que non se trata dun fenómeno illado nin pouco significativo.

En xeral, as investigacións levadas a cabo nestas áreas demostran a existencia de trastornos de identidade e alteracións nas vidas das persoas emigradas, sexan retornadas ou non. Imolo ver con máis detalle nestes dous estudos dos ámbitos da psiquiatría e da antropoloxía, que nos amosarán as consecuencias reais, mais non sempre visibles, do retorno.

\subsection{Unha visión psicolóxica}

Unha das achegas máis relevantes sobre o retorno no eido da saúde mental é o ensaio Psicopatoloxía do retorno (2007), escrito polos psiquiatras Alexandre García-Caballero e Ramón Area Carracedo. Este título tan revelador xa é un indicativo claro do que é unha realidade: que volver á terra propia pode causar alteracións na saúde da persoa. Nesta obra, os autores compilan as historias clínicas de varios doentes que foron atendidos na súa consulta e que están relacionadas, directa ou indirectamente, co regreso á terra natal.

A narración dos pacientes non deixa lugar a dúbidas sobre a dureza dunha experiencia que describen con moita tristeza, dor, pena e frustración, e na que sentiron o peso da soidade e da incomprensión. Por outro lado, os diagnósticos dos psiquiatras tampouco son moi alentadores; falan de depresión, ansiedade, trastorno da personalidade, bipolaridade, alcoholismo, demencia, etcétera.

Repasando as causas que motivan o regreso do emigrante, os autores sitúan en primeiro lugar o reencontro coa familia e coa terra, para facilitar así a restauración do vínculo que quedou interrompido pola marcha. Pero detrás deste motivo principal, que non é outra cousa que a morriña, hai outras motivacións secundarias que moitas veces quedan ocultas e que son as que finalmente acaban desencadeando os conflitos. Trátase da culpa, a inadaptación, o fracaso, a arrogancia ou a presión temporal, que detallaremos a continuación.

O sentimento de culpabilidade aparece ante o abandono dos pais, os fillos, os familiares, os amigos ou a terra, e impide que o emigrado viva satisfactoriamente no exterior. Así, a culpa actúa como unha barreira tan difícil de superar que causa o illamento do emigrante e acrecenta a súa intención de escapar.

Tamén a inadaptación produce un efecto similar. O feito de non afacerse ao lugar de destino quizais non impide a estancia alá, pero en calquera caso non permite a integración. As dificultades que aparecen, como o idioma, o cambio cultural, a pertenza á comunidade ou o clima aumentan a ansiedade e converten o desexo do regreso nunha fuxida. 
Outras veces o emigrante volve por necesidades económicas. Se as cousas non foron ben na emigración, a única opción é o regreso, sendo habitual que o retornado agoche a situación real e que disfrace o fracaso.

A necesidade de amosar a mellora económica, social ou cultural no lugar natal tamén é un motivo para a volta, que vén acompañada dunha certa actitude arrogante. Así, é típica a compra de vehículos de gama alta e a construción de edificios senlleiros ou chalés nas aforas da aldea para amosar o novo status e consolidar o ascenso diante da comunidade.

Por último, o autoconvencemento de que a estancia no outro lugar era provisional e tiña que rematar fai que a persoa poña punto e final a esa etapa, sen valorar adecuadamente as causas reais desa decisión. Nestes casos, a presión polo tempo vivido na terra adoptiva faise insoportable e prodúcese un retorno precipitado, inconsciente ou pouco meditado.

Independentemente dos motivos para o regreso, como os que acabamos de resumir, unha vez tomada a decisión de volver ábrese de novo a porta ao descoñecido, e iso é algo que moitos retornados non teñen en conta, pois non conciben que o tempo pasou e que o que eles coñeceron xa non existe. Así, cando se produce o regreso, estas persoas enfróntanse a unha situación para a que non estaban preparadas. Pero que é o que atopan que tanto malestar lles produce?

Principalmente, cambios. Nas persoas que quedaron, nos lugares que frecuentaban, nas paisaxes, nas vilas ou no contorno. Pero ademais, hai cambios a grande escala, na sociedade, a economía, a cultura e a política do país. Ás veces ven que todo está moi cambiado, sobre todo, en comparación cos bos recordos que gardaban na memoria; outras veces comproban con desagrado que hai cousas que non cambiaron nada. Nese punto, os retornados son conscientes de que os que cambiaron foron eles mesmos. Ven que o lugar ao que regresaron non existe e que as persoas do pasado son outras. O conflito está servido.

Mais neste ambiente de confrontación, non podemos centrarnos só nos retornados, pois o contorno que os recibe tamén experimenta cambios polo regreso dos que noutro tempo foran "os seus". Se o emigrante ten que integrarse de novo, o seu círculo ten que facer unha nova acollida, e iso, como veremos a continuación, tampouco é doado.

Por exemplo, se falamos de roles de xénero, moitas mulleres retornadas que durante a emigración eran independentes e traballaban, ao volver ao seu país acaban recluídas na casa. Na mesma liña, moitos homes danse conta de que está mal visto que colaboren no ámbito doméstico. Esta falta de equidade na terra natal fai que o regreso se perciba como un retroceso.

En canto á pertenza á comunidade, habitualmente as persoas que retornan queren sentirse útiles, participar nas actividades da zona ou intercambiar experiencias, por exemplo. Pero vense rexeitadas pola súa comunidade, que se sente intimidada. Os retornados, que queren integrarse, reaccionan agochando os seus méritos ou ocultando a súa nova personalidade por vergonza, por medo ás envexas ou por intentar encaixar na comunidade. E así, créase un círculo vicioso no que todos desconfían de todos.

Tamén aparecen problemas en parellas que traballaban todo o día e non pasaban tempo xuntas. Iso facilitaba a convivencia e agochaba as súas diferenzas, pero unha vez xubilados os dous, están obrigados a convivir e discuten. Danse conta de que non se coñecen ou non se soportan. Non é raro que finalmente se separen.

Do mesmo modo, tras o regreso, emerxen moitos conflitos familiares relacionados coas herdanzas. Os retornados queren repartir as pertenzas, arranxar os papeis e deixalo todo amañado, pero chocan coa inmobilidade dos que quedaron na casa, que non están dispostos a cambiar nada. Xorden as envexas na familia, os resentimentos, as culpas, os reproches e as acusacións mutuas de ter escapado da casa ou de querelo todo sen facer nada.

A nivel político, os emigrantes accederon a novos sistemas de participación democrática no país de acollida, que deixaron en evidencia o atraso da ditadura implantada no país natal. Non obstante, os que regresaron a España na democracia atoparon unha política caciquil que lles creou, unha vez máis, a mesma sensación de retroceso.

No núcleo familiar, emerxen conflitos nas relacións entre pais e fillos. Ás veces os pais emigraban e deixaban os fillos ao coidado dos avós, considerando que a estancia era temporal. Pero o tempo pasaba, os pais non volvían e os fillos acababan sendo criados polos avós e rexeitando aos pais á súa volta. Outras veces, nacían os fillos na emigración, afacíanse á nova cultura e despois non querían viaxar cos pais a un país que non consideraban seu, porque xa crearan vínculos ou tiveran familia; ou ben, se volvían cos pais, non se adaptaban e querían regresar ao país que si consideraban seu. 
En canto á mentalidade en xeral, desaparece a identificación coa forma de pensar do país natal, tras coñecer outras culturas de fóra. As persoas retornadas emiten xuízos de valor sobre o propio país en canto á súa falta de compromiso, comodidade, desmemoria ou despreocupación. E ese xuízo crea un malestar visible na comunidade natal, que pecha as portas ás experiencias alleas. Así, os retornados botan de menos o país adoptivo e viven unha segunda morriña.

Por último, aparecen dificultades de comunicación. No caso de Galicia, por exemplo, a forma de ser reservada ou prudente dos galegos choca radicalmente coa necesidade dos retornados de expresar os seus sentimentos e superar así o trauma. O retornado rexeita o que considera que é unha actitude supersticiosa, e o galego desconfía do que percibe como unha esaxerada apertura emocional por parte do retornado.

Así, con todos estes desencontros, o máis habitual é que se produza a inadaptación ao lugar propio; a un lugar que estivo idealizado na mente do emigrante durante moito tempo. As consecuencias desta inadaptación maniféstanse en forma de depresións, ansiedade, angustia, adiccións como o alcoholismo e, en xeral, crearán todo tipo de traumas.

Os autores codifican todas estas vivencias mediante conceptos como o de restaurar a "mala acción" polo abandono da terra, identificada como nai; a frustración do proxecto vital, cando non se cumpren as expectativas da marcha e do retorno; a metáfora do retorno ao paraíso, que é inexistente; o modelo de educación "sacrificial", que esixe unha compensación polo sacrificio feito; a inadaptación crónica, que non permite a adaptación en ningures; o choque cultural inverso, causado polo impacto da cultura propia; a idealización da comunidade de acollida e a desvalorización da comunidade natal, tamén coñecida como "segunda morriña"; ou as dificultades pragmáticas, que amosan as diferenzas comunicativas e emocionais entre os retornados e o contorno.

O certo é que volver implica recoñecer a orixe pobre. E non só iso; ademais, os retornados teñen que contrastar as súas "lembranzas do futuro", cunha realidade que xa non recoñecen, pois nin eles nin o mundo que deixaron atrás son os mesmos. Así o expresan os autores neste fragmento (2007: 31):

O emigrante cando marchou tivo que adaptarse a unha nova cultura, a un novo contorno, a un novo clima e incluso a outro idioma. Ao facer isto converteuse noutro (...). Volver implica en certa medida renunciar a ese outro que fomos, e transformarnos outra vez noutro distinto, parecido a aquel que partiu, que é o que na casa esperan ver chegar. É un imposible.

En definitiva, a información proporcionada neste ensaio xa supón un bo punto de partida para analizar as consecuencias que produce a emigración de retorno, provocando conflitos na identidade ata o punto de causar enfermidades e trastornos mentais. Ademais, os autores salientan a incidencia da somatización da dor da alma, que se manifesta en enfermidades de todo tipo, máis alá do ámbito psicolóxico.

\subsection{Unha visión antropolóxica}

Desde outro punto de vista, o ensaio Viaxe sen retorno (2014), do antropólogo Manuel Mandianes, analiza as etapas de todo o acto migratorio, desde a motivación inicial ata a adaptación ou inadaptación final, pasando por fases intermedias como a ilusión, a decepción, o desengano, a esperanza ou o desarraigo.

Para a elaboración deste estudo, o autor pasou máis de 10 anos entrevistando emigrantes e escoitando en primeira persoa as voces da emigración. As testemuñas que nos ofrece proporcionan unha visión moi completa e humanizada do fenómeno migratorio e achégannos aos dramas persoais que se agochan detrás de cada historia. Destacan moitas reflexións interesantísimas neste libro, pero extraeremos as que fan referencia directa ao retorno ou inflúen nel.

Comenta Mandianes que a emigración é unha viaxe que ten moitas motivacións (económicas, políticas, persoais, etcétera), pero que realmente xira arredor dunha busca interior. Se a persoa non emigra sendo consciente disto, vivirá un engano, quererá volver e estará en conflito consigo mesma toda a vida, incluso aínda que regrese. Hai que ter en conta que, en moitos casos, a emigración é unha escusa (non recoñecida pola propia persoa) para romper co pasado ou para cambiar de vida. É unha escusa para fuxir. E a fuxida, aínda que é unha solución temporal, non soluciona o problema de fondo, que en moitos casos é o da identidade.

Por outro lado, o autor salienta que a emigración é unha etapa de ruptura e de contradición; hai pais sen fillos, avós sen netos, xente sen mortos ou xente sen lingua nin tradición. E o retorno é un intento de recompoñer os anacos desa historia que quedou rota. $\mathrm{O}$ encontro coa 
outra cultura pode ser positivo (e así se produciría unha asimilación da cultura) ou pode ser negativo (entón falariamos de choque cultural). E iso incide directamente nos motivos para retornar. A persoa non se adapta; gustaríalle desfacer a viaxe e non ter tomado a decisión de marchar, pero volver atrás xa non é posible.

Tamén en moitos casos non hai integración e se produce o illamento da persoa, de maneira que non coñece xente, non aprende o idioma, só se relaciona coa súa xente e non sae do barrio ou da cidade. Este illamento vai facer presión para a volta ao lugar propio, onde idealmente todos os problemas quedarían solucionados.

Afirma Mandianes que a división do emigrante é permanente. E o único permanente que hai na súa vida. Sabe que rompeu coa terra natal e, aínda que se aferra ao retorno, comprende que volver é enfrontarse a unha nova emigración e que o lugar de orixe só existe na súa imaxinación. Pero ansía volver e está convencido da súa volta, como o caso desta testemuña, recollida no libro (2014: 48): "Eu non estou aquí, senón que vou de paso", dun galego que levaba vinte anos en Colonia.

A conclusión que extraemos deste ensaio vén reflectida no propio título: a emigración é unha viaxe sen retorno. Indica que o que marcha, marchou (de si mesmo) para sempre. E este sentimento aparece nas moitas testemuñas ofrecidas polo autor, das que podemos mencionar algunhas: "Aínda que volvan, ninguén volve ao país que soñaba mentres estaba lonxe. Por iso se senten estraños no seu país" (Ibid.: 165); "Volvemos aquí, pero seguimos alí, e cando estamos alí, seguimos aquí" (Ibid.: 168); "Cando un está lonxe e sen información, cre que as cousas terían cambiado para ben. Pero cando volve dáse cos fociños contra a realidade" (Ibid.: 169); "O problema dos que marchamos é o regreso" (Ibid.: 173).

Como vemos, o estudo ofrécenos algo moi similar á experiencia recollida en Psicopatoloxía do retorno; ou polo menos, complementa bastante a información sobre o fenómeno do retorno e lévanos á mesma conclusión. O retorno causa conflitos na identidade, e obviamente non é doado pasar por esa situación, pero o retorno non é o problema, senón o detonante, pois fai que se manifeste algún problema previo relacionado coa identidade, a autoestima ou a personalidade, entre outros.

Mandianes afirma que unha das claves destes desencontros está na orixe da propia emigración, pois "con frecuencia, ao emigrante, máis que o desexo de atopar o paraíso, empúxao o desexo de fuxir [...]. A emigración é, a longo prazo, unha revelación do que quere fuxir e ocultarse" (Ibid.: 175). E, en certo modo, constrúe unha mensaxe positiva, afastada da compaixón, que ofrece unha nova visión da experiencia da migración:

O emigrante é a persoa que recibiu o privilexio de facer prospeccións do mundo no seu interior; e moitos así o fan, pero non deixará xamais de ser unha persoa escindida, dividida e encanta$\mathrm{da} /$ desencantada de descubrir un mundo novo moi diferente do seu orixinal. (...) Só na ficción, xamais na realidade, se pode atopar unha cousa sen achar o seu oposto. (Ibid.: 177)

\section{O retorno na ficción: narrativas do regreso}

Unha vez comentadas as perspectivas da psiquiatría e da antropoloxía sobre o retorno, con testemuñas reais de pacientes e de persoas entrevistadas, abordaremos o punto de vista literario, pois non debemos esquecer o papel imprescindible da literatura na representación das distintas experiencias vividas.

Sabemos que a literatura do exilio é moi abundante, pero como apuntamos antes, está máis centrada na ida que na volta. Por iso queremos mencionar catro exemplos (dúas novelas e dous ensaios autobiográficos) extraídos da literatura peninsular de posguerra nos que o retorno é o tema principal.

$\mathrm{Na}$ novela galega $O$ exiliado e a primavera (2004), de Manuel Veiga, coñecemos a historia de Alexandre Marrube, un exiliado en México que regresa á cidade natal para enterrar a súa nai. Despois de case 40 anos de exilio, o protagonista atopa unha terra e unha sociedade que non recoñece, e esta experiencia causa nel un impacto brutal.

O retornado sabe que o que deixou atrás xa non existe, pero non pode evitar fabular cos recordos da súa infancia: o barrio da estación, os barrios campesiños, os palleiros, as hortas, as leiras, o río no que se bañaba de cativo... Pero os recordos contrastan coa realidade e, no seu lugar, atopará edificios, chalés, barrios urbanos, estradas e unha enorme presa no río onde se bañaba:

O Cabe parecía o mesmo, pero xa non era o Cabe, aquel río no que os cativos se enxaboaban e bañaban cando nas casas non había nin cuarto de aseo, nin sequera auga corrente [...]. Agora, grazas a unha presa, parecía máis grande, pero ao 
velo de preto un desilusionábase coas súas augas estantías, mortas coma nun estanque. (2004: 28)

Axiña iremos vendo un home abatido polos cambios e decepcionado pola actitude dunha sociedade consumista que está totalmente falta de compromiso, que é pobre intelectualmente e que esqueceu a súa historia máis recente. Séntese menosprezado e así o expresa neste fragmento:

Volves e non es ninguén, eu non son ninguén para ti. Que agardaba? Ser tratado coma un anxo que vén facer a súa boa acción ou como un pai que vén dar os seus consellos? Quizais. Pero os que debían ser os teus fillos non te recoñecen. Non teñen o teu carácter, non comparten nada. (Ibid.: 109)

Hai un caso similar na novela La raíz rota (1952), de Arturo Barea, que exemplifica o retorno do exilio e magnifica o desarraigo. O protagonista, Antolín Moreno, regresa a España do seu exilio en Londres e reúnese cunha familia que non ten nada que ver coa que deixara atrás hai uns anos. A súa muller fai espiritismo, a filla fíxose beata, un dos fillos é comunista e o outro, falanxista. Ante ese panorama desolador, o home regresa a Londres:

No es verdad que en Londres fuera infeliz. Lo era a medias, mitad feliz, mitad miserable, porque siempre estaba pensando si no me sentiría menos solo entre gente que hablara mi lengua. Eso se acabó. Claro que voy a ser toda mi vida un extranjero en Inglaterra; pero aquí también soy extranjero, y esta clase de soledad es peor y me hiere mucho más, porque me hiere en la propia carne. (2009: 292)

É certo que Arturo Barea, que estivo exiliado en Inglaterra, nunca regresou a España e quizais os personaxes desta novela poden parecer un pouco estereotipados. Mais a súa visión do retorno non é fabulada, pois reflicte a ruptura, a inadaptación, o atraso dunha sociedade enferma, e, en xeral, os conflitos desa identidade que se busca a si mesma.

Noutra liña, mencionamos as experiencias de dous escritores retornados que reflectiron a experiencia do regreso e do encontro coas súas raíces. É o caso de Max Aub e María Luísa Elío, que visitaron o país despois de vivir moitos anos exiliados.

O ensaio La gallina ciega. Diario español (1971), de Max Aub, describe a visita do escritor a España a finais dos anos 60. Falamos de visita, porque nunca regresou definitivamente a España.

La gallina ciega é un retrato imprescindible, xa non da España do final da ditadura, senón do que supón o retorno do exiliado. $\mathrm{O}$ testemuño do autor deixa ver a profunda decepción sufrida pola distancia existente entre o país idealizado na súa cabeza e o país real; un país dominado polo conformismo, o esquecemento ou a desmemoria. Así o expresa este exemplo:

Ni estamos -mi generación- en el mapa. Todo es paz. Es curioso cómo eso de los veinticinco -o treinta- años de paz ha hecho mella, o se ha metido en el meollo de los españoles. No se acuerdan de la guerra -ni de la nuestra ni de la mundial-, han olvidado la represión o por lo menos la han aceptado. Ha quedado atrás. Bien. (2015: 251)

O autor fala das cousas con mordacidade, con aire reivindicativo, con ironía e sarcasmo, e faino para criticar a parálise moral da sociedade; unha situación que lle fai sentirse como un estranxeiro en España e regresar a México. E así, di: "Soy un turista al revés; vengo a ver lo que ya no existe" (Ibid.: 245).

Tamén María Luisa Elío, no seu ensaio autobiográfico Tiempo de llorar (1988), relata o regreso, que tampouco foi definitivo, á súa cidade natal, Pamplona, despois de máis de 30 anos de exilio en México.

O estilo empregado por Elío é distinto ao de Aub, xa que ela lembra con moitísima tristeza e nostalxia un pasado que sabe que é imposible recuperar e que foi truncado pola guerra: os seus pais, as súas irmás, o barrio, o balcón da súa casa... Malia ser consciente diso, recrea na súa mente eses recordos e elabora "recordos dun futuro" que non vai existir. O reencontro coa súa cidade faille ver a fraxilidade da súa identidade, e pouco a pouco irá descubrindo os enganos da memoria:

Hacía mucho frío, llovía, y en un letrero como cualquier otro decía: PAMPLONA. Ahora ya podía volver, y tenía la certeza, con sólo mirar el letrero, que la gente estaba muerta. [...] Me habían quitado el pasado. Ahora me quitaban el recuerdo del pasado, del que yo hacía el presente, y sin tener ninguno de los dos me era imposible pensar en el futuro. ¿Cómo puede haber un futuro sin pasado ni presente? (2002: 21-22)

Son reflexións cheas de amargura, que evocan unha infancia perdida polo paso do tempo, rota 
pola guerra e polo exilio. A mirada de María Luisa Elío é interior totalmente; diríxese cara á dor da alma e lamenta a perda da súa identidade. Neste caso, o dó faise por esa perda interna, que unha e outra vez intenta confirmar:

$\mathrm{Y}$ ahora me doy cuenta de que regresar es irse. Es decir, que volver a Pamplona es irse de Pamplona. Al fin voy a volver donde las cosas no están ya. [...] Ahora sé que la mirada tan sólo va a servir para borrar. Lo sé, lo sabía, y en ese saber tiene una importancia total el verificar Pamplona, tan sólo un lugar. (Ibid.: 19)

\section{Conclusións}

Probablemente, Claudio Guillén ofrece unha das visións máis acertadas sobre o fenómeno do retorno cando fala do destempo: "La recuperación del espacio es ilusoria. O imposible (...). La temporalidad moderna es lo que hace que el regreso del exiliado a su propio país sea tantas veces amargo, problemático, irreal" (2007: 88). Precisamente, esa falta de sincronía é a causante de moitos dos conflitos que comentamos, xa que os recordos (reais ou inventados) van por un lado e a realidade, por outro.

Mais cando se fala do retorno, o máis habitual é pensar en conceptos como o da volta ao fogar, a recompensa polo esforzo realizado ou a reparación dunha situación inxusta. Esta é a secuencia lóxica e, automaticamente, creamos unha imaxe en positivo do acto de retornar. No caso da literatura, por exemplo, pensamos en personaxes que marchan cara ao descoñecido, enfrontan dificultades, volven á casa, reúnense coa familia e viven en completa harmonía e felicidade.

Pero sabemos que esta fórmula dos finais felices non sempre se cumpre; e temos referen- cias dabondo que confirman que retornar quizais non é unha boa idea e que moitas veces non dá o resultado esperado. Tanto na literatura como na vida real, tal e como vimos brevemente neste estudo, os trastornos causados polo retorno na identidade e nas vidas das persoas retornadas son máis que evidentes.

Se a identidade do emigrante pode definirse como "unha identidade entre paréntese, entre algo e algo", en palabras dos psiquiatras Area Carracedo e García Caballero (2007: 99), a do retornado é "unha identidade fráxil supeditada ao paradoxo da volta e organizada ao redor da idea de sacrificio por un ben maior intanxible e sempre esvaradizo" (Ibid.: 99).

Isto significa que retornar implica enfrontarnos ao pasado; a eses problemas que quedaron sen resolver ou a eses sentimentos que durante tanto tempo preferimos ignorar. Significa que os conflitos que deixamos atrás, disimulados por unha distancia xeográfica que deu lugar a unha distancia emocional, volverán aparecer. En realidade, sempre estiveron aí.

Por iso, quizais, nos resulta incómodo o fenómeno do retorno e tamén falar del. Porque nos obriga a mirar cara a dentro, facer balance e valorar cal foi a nosa evolución, se a houbo. E este exercicio, que é como un exame, ás veces revélanos cousas que non nos gustan.

Quizais unha das mellores reflexións que podemos extraer é a da elección consciente do camiño vital: ao ir e ao vir; na marcha e no regreso. Cando unha persoa se responsabiliza do rumbo que lle vai dar á súa vida e acepta as consecuencias desta decisión, calquera que sexan, non precisa escapar de si mesma, nin tampouco dá pasos atrás para refacer o camiño, volvendo a fuxir. O certo é que fuxir das cousas nos encadea a elas, pero enfrontalas nos libera.

\section{Referencias bibliográficas}

Aub, Max (2015 [1971]): La gallina ciega. Diario español. Madrid: Visor.

Area Carracedo, Ramón e Alexandre García Caballero (2007): Psicopatoloxía do retorno. Vigo: Galaxia.

Aznar Soler, Manuel; José Ramón López García, Francisca Montiel Rayo e Juan Rodríguez Rodríguez (coords.) (2014): El exilio republicano de 1939. Viajes y retornos. Sevilla: Renacimiento.

Barea, Arturo (2009 [1952]): La raíz rota. Madrid: Salto de página.

Elío, María Luisa (2002 [1988]): Tiempo de llorar y otros relatos. Madrid: Turner.

Guillén, Claudio (2007 [1988]): Múltiples moradas. Ensayo de literatura comparada. Barcelona: Tusquets. Jato, Mónica; Sharon Keefe Ugalde e Janet Pérez (coords.) (2009): Mujer, creación y exilio. Barcelona: Icaria.

Mandianes, Manuel (2014): Viaxe sen retorno. Santiago de Compostela: Sotelo Blanco.

Veiga, Manuel (2004): O exiliado e a primavera. Vigo: Xerais. 